\title{
New Attachment to Periodontally Diseased Root Surfaces Treated with Hydrochloric Acid
}

\author{
Tetsuji Ogawa, Hiroyuki Kawaguchi, Yuri Fujitani, Hiroshi Yoshino, Mu-Fei Liu, Joviniano M Oliveira Jr, \\ Keiji Nakanishi, Tomie Higashi and Hidemi Kurihara \\ Department of Endodontology and Periodontology, Hiroshima University School of Dentistry, Hiroshima, Japan
}

\begin{abstract}
Ogawa T, Kawaguchi H, Fujitani Y, Yoshino H, Liu MF, Oliveira JM Jr, Nakanishi K, Higashi $T$ and Kurihara $H$. New attachment to periodontally diseased root surfaces treated with hydrochloric acid. Oral Med Pathol 1996;1:23 28. ISSN 1342-0984.
\end{abstract}

\begin{abstract}
Experimental periodontitis was induced in the premolars of two adult beagle dogs by cotton ligature placement and administration of a soft diet that facilitated plaque accumulation over 24 weeks. Periodontal flap surgery, including root planing was carried out by using curettes and root demineralization with $0.3 \mathrm{~N}$ hydrochloric acid (HA) for $5 \mathrm{~min}$. In the HAdemineralized group, new cementum formation was seen on the non-resorbed dentin surfaces, and the newly formed cementum matrix fibers became interlaced and/or attached to the exposed dentin matrix fibers through an amorphous granular substance. In the non-HAdemineralized control group, the regenerated junctional epithelium covered the planed dentin surface, and no new cementum formation was observed. The present study suggests that 0.3N HA treatment can induce the formation of new connective tissue attachment to a previously diseased root surface.
\end{abstract}

Key Words: new connective tissue attachment, new cementum formation, hydrochloric acid, periodontally diseased root surfaces

Tetsuji Ogawa, Department of Endodontology and Periodontology, Hiroshima University School of Dentistry, 1-2-3 Kasumi, Minami-ku, Hiroshima 734, Japan

\section{Introduction}

Although various procedures have attempted to induce new connective tissue attachment on the previously diseased root surface, these procedures have lacked complete predictability (1). Among these suggested procedures are root demineralization using citric acid and other chemical agents, and guided tissue regeneration (GTR). It is important to note that demineralization of the root surface by acids can accelerate the new cementum formation. The role of citric acid treatment in periodontal therapy and periodontal regeneration is controversial. The rationale for this procedure is based on several in vitro studies, animal models, and human trials that described the occurrence of new connective tissue attachment after root surface demineralization. The biological basis for the success of root demineralization might be related to exposure of dentin collagen fibrils and non-collagenous matrix $(1,2)$.

Hydrochloric acid (HA) has been used to demineralize the dentin surface and used to extract bone morphogenetic protein, which has osteoinductive properties, from bone $(3,4)$ and dentin (5). HA-demineralization is regarded as more efficient than citric acid at inducing the regenerative cementogenesis process (6). Moreover, partially demineralized dentin has induced new bone and cementum-like tissue formation (7-11). However, few studies have been conducted using HA demineralization, because a high concentration of HA is considered to be an irritant to hard and soft tissues (12). We have previously examined the ideal concentration and application time for HA in periodontal wounds (13) and concluded that treatment with $0.3 \mathrm{~N} \mathrm{HA}$ for 5 min on denuded dentin surfaces is the best for inducing new cementum formation $(14,15)$.

This current study was designed to examine the effects of HA-treatment on periodontally diseased dentin surfaces in inducing new connective tissue attachment.

\section{Materials and Methods}

Surgical procedures

Experiments were performed on the lower premolars of two adult beagle dogs. Good oral health was established by scaling and plaque control through topical application of $0.2 \%$ chlorehexidine and mechanical tooth brushing (3 times/week). Experimental periodontitis was induced by placing a cotton ligature in the sulci of the second, third, and fourth premolars, and accelerated plaque accumulation was facilitated by feeding the animals a soft diet. When periodontitis was established after 24 weeks (Fig.1a), periodontal flap surgery was performed on each animal under general anesthesia with Nembutal ${ }^{\circledR}$. Following flap reflection, root surfaces were 

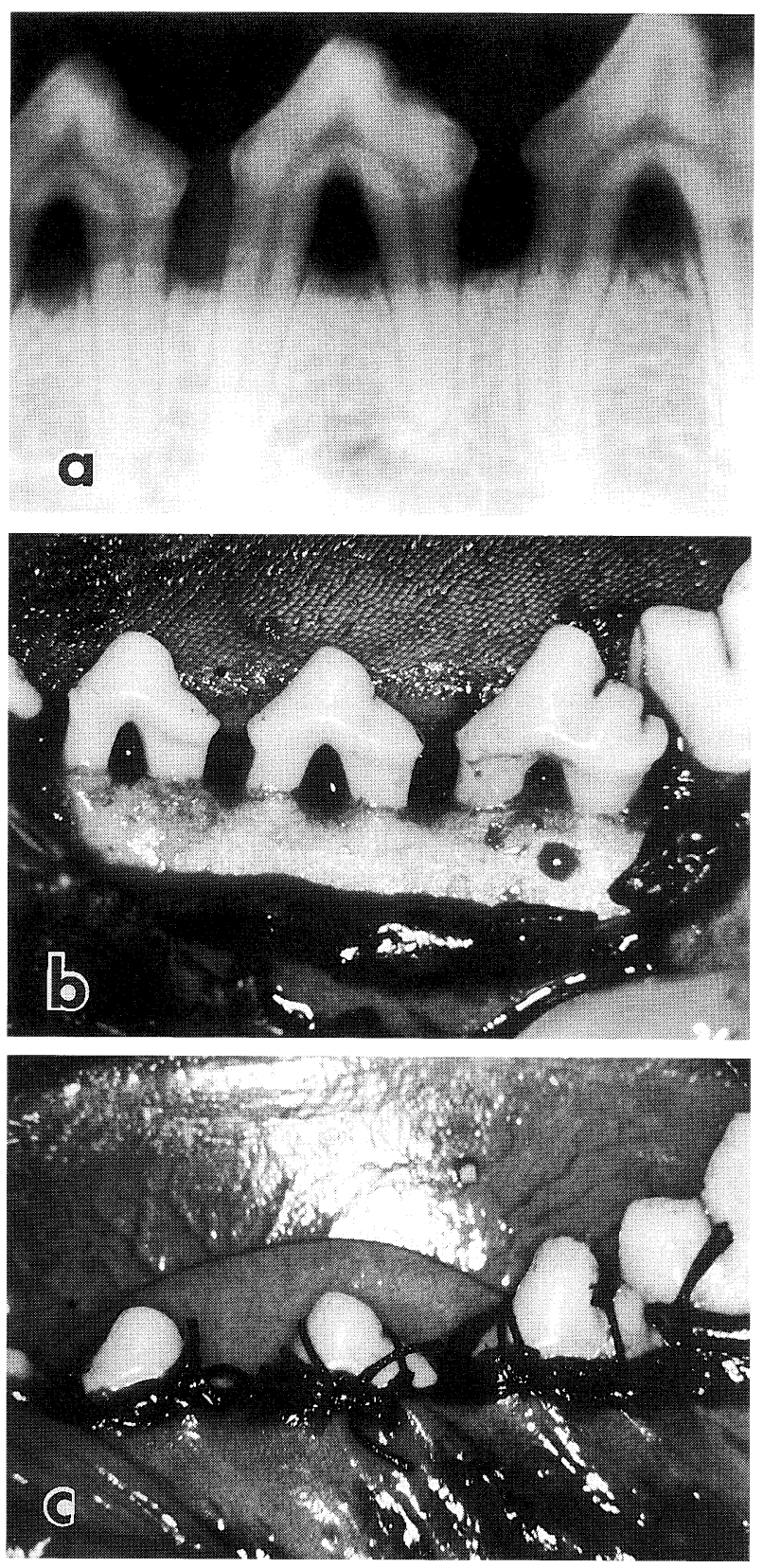

Fig.1: Presurgical X-ray photograph of the experimentally induced periodontitis mandibular premolar area (a); following muco-periosteal flap elevation (b); following repositioning of gingival flap and suturing (c).

planed using curettes (Fig.1b). Small cotton pellets soaked in $0.3 \mathrm{~N}$ HA were applied to the root surfaces of the second and fourth premolars for $5 \mathrm{~min}$, followed by abundant irrigation with saline. The roots of the third premolars were covered with a rubber dam during topical application of HA and remained as non-demineralized control sites. Finally, gingival flaps were coronally positioned at $2 \mathrm{~mm}$ from the cemento-enamel junction and sutured (Fig. 1c). Postoperatively, the oral hygiene of each animal was reestablished by means of the above described plaque control methods.

Histological procedures

At 4 and 8 weeks after surgery, each animal was perfused with $1 \%$ glutaraldehyde under deep anesthesia, and the jaws, including teeth and periodontal tissues, were removed. Jaws were immersed immediately in
$2.5 \%$ glutaraldehyde- $2 \%$ paraformaldehyde in $0.1 \mathrm{M}$ sodium cacodylate buffer ( $\mathrm{pH} 7.4$ ) at $4^{\circ} \mathrm{C}$ for overnight and decalcified in $10 \%$ EDTA $(\mathrm{pH} 7.4)$ at $4^{\circ} \mathrm{C}$ for 2 months. Then each jaw was trimmed and sliced mesiodistally through the midline of each root into blocks including tooth and periodontal tissues. Each block was postfixed with $1 \%$ osmium tetraoxide in sodium cacodylate buffer at $4^{\circ} \mathrm{C}$ for $2 \mathrm{~h}$, dehydrated in a graded alcohol series, and embedded in Epon 812. Thick sections were stained with toluidine blue and observed with a light microscope. Ultra-thin sections were stained with uranyl acetate-lead citrate and tannic acid and observed with a JEOL JEM-100S transmission electron microscope.

\section{Results \\ HA-demineralized experimental group}

At 4 weeks after surgery, light microscopical findings revealed that, under the regenerated junctional epithelium, the newly formed connective tissue attached to the smooth and non-resorbed dentin surfaces (Fig. 2a). Electron microscopy illustrated that an electron dense zone, which is considered to be a result of HA-demineralization, was present on the dentin surface, and few dentin matrix fibers were exposed. New collagen fibril formation was seen on the dentin surface, and cementoblastlike cells including cell organelles, were in close contact with the electron-dense dentin surface (Fig. 2b). At the most apical position of the demineralized dentin surfaces, where the new cementum deposits were seen, a granular amorphous substance, which did not include collagen fibrils, was deposited between the electrondense line of the dentin surface and the new cementum matrix fibers (Fig. 2c).

At 8 weeks after surgery, light microscopic examination of the coronal site indicated that the new cementum matrix and functionally oriented fibers were seen on the non-resorbed dentin surface adjacent to the apical end of regenerated junctional epithelium (Fig. 3a). In electron micrographs, the dentin matrix fibers exposed by HAdemineralization were interlaced with the newly formed cementum matrix fibers (Fig. 3b). Amorphous granular patches 0.1-0.5 $\mu \mathrm{m}$ in thickness were frequently deposited on exposed dentin fibers, where new cementum matrix was formed (Fig. 3c). At the most apical site of the demineralized dentin surface, a basophilic line was often recognized between the dentin surface and the new cementum matrix in light microscopic analysis (Fig.3d). The new cementum matrix fibers were arranged both parallel and perpendicular to the amorphous granular layer of the dentin surface (Fig. 3e).

\section{Non-HA-demineralized experimental group}

Light microscopic examination at 4 and 8 weeks after surgery revealed that regenerated junctional epithelial cells had migrated apically and covered the planed dentin surface. New connective tissue attachment was not observed on the dentin surface (Fig. 4). 

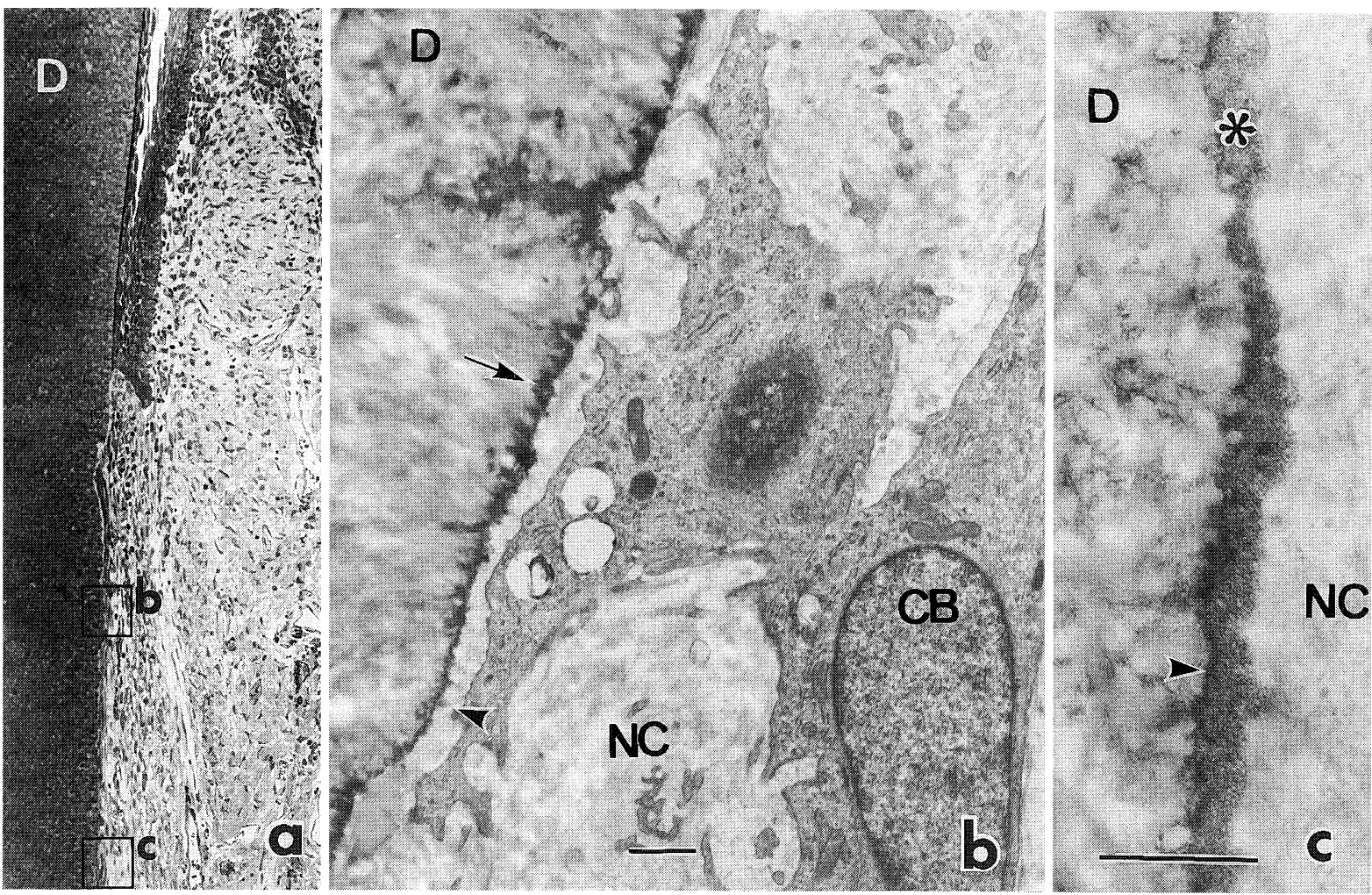

Fig. 2: Findings with HA-demineralized experimental group at 4 weeks after surgery.

a: Light microscopic photograph. Under the regenerated junctional epithelium, newly formed connective tissue attaches to smooth and non-resorbed dentin (D) surfaces. Toluidine blue staining $(\times 80)$

b: Electron microscopic photograph of connective tissue attachment of area in Fig. a. A few dentin matrix fibers are exposed by HA-demineralization (arrowhead), and electron dense materials (arrow) are deposited on dentin (D) surface. Newly formed collagen fibrils (NC) are seen on dentin surface, and a cementoblast-like cell (CB) including cell organelles, is in close contact to dentin surface. Uranyl acetate and lead citrate staining $(\times 7,600$, Bar: $1 \mu \mathrm{m})$.

c: Electron microscopic photograph of apical dentin surface in Fig a. A granular amorphous substance $(*)$, which does not include collagen fibrils, is often deposited between the electron dense dentin line (arrowhead) of the dentin surface (D) and the new cementum matrix (NC) fibers. Uranyl acetate and lead citrate staining ( $\times 19,000$, Bar: $1 \mu \mathrm{m})$.

\section{Discussion}

Although many clinical and animal studies using citric acid as a root conditioner have been reported, its effectiveness for new cementum formation is still controversial (1). Conversely, HA has not been used routinely, because it is considered to be more of an irritant than citric acid. Although a high concentration of acid is considered to be deleterious for periodontal tissues (12), Register et al. $(11,12)$ and Inoue et al. (6) reported that HA-demineralized dentin matrix is able to induce more new cementum-like tissue formation than citric acid treated dentin. In previous reports, a concentration of $0.6 \mathrm{~N}$ HA has been used to achieve partial dentin demineralization (7-10). However, our more recent studies have revealed that a $0.3 \mathrm{~N}$ HA-demineralization of dentin surfaces for 5 min does less damage to periodontal tissues than a $0.6 \mathrm{~N}$ HA demineralization (13). In addition, the $0.3 \mathrm{~N}$ HA treatment is more effective at forming new cementum without dentin resorption in periodontal surgery $(14,15)$.

This study shows that new cementum is directly formed on the HA-treated dentin surfaces without dentin resorption. This finding is consistent with the previous results of Register et al. $(11,12)$ and our results (13-15). HA-demineralized dentin may not promote fiber attachment to exposed collagen fibers, in contrast to the behavior seen when demineralization is precipitated by citric acid (16-18). Inoue et al. further questioned the use of citric acid, reporting that the root conditioning with HA was more effective in inducing cementum formation on dentin (6). Previous findings that bone morphogenetic protein is extracted by HA-demineralization and can induce cartilage and bone formation $(3,4,9)$, that partially demineralized dentin induces cementum-like tissue (5-8), and that bone morphogenetic proteins are found in dentin (8) also suggest the usefulness of HA-demineralization. Previous reports $(6,13-15)$ and this study supports the theory that HA-treated dentin has the ability to induce new cementum formation. this might indicate that the cementum formation process is different from the process that happens after citric acid treatment. Our present findings indicate that bone morphogenetic protein in dentin matrix demineralized by HA might promote the differentiation of cells originating from periodontal ligament and alveolar bone. An amorphous granular layer between the dentin surface and new cementum has been demonstrated in previous reports (19-22). This granular structure is similar to the reversal line present between the dentin surface resorbed by odontoclasts and new cementum (23), the interface between new bone and 

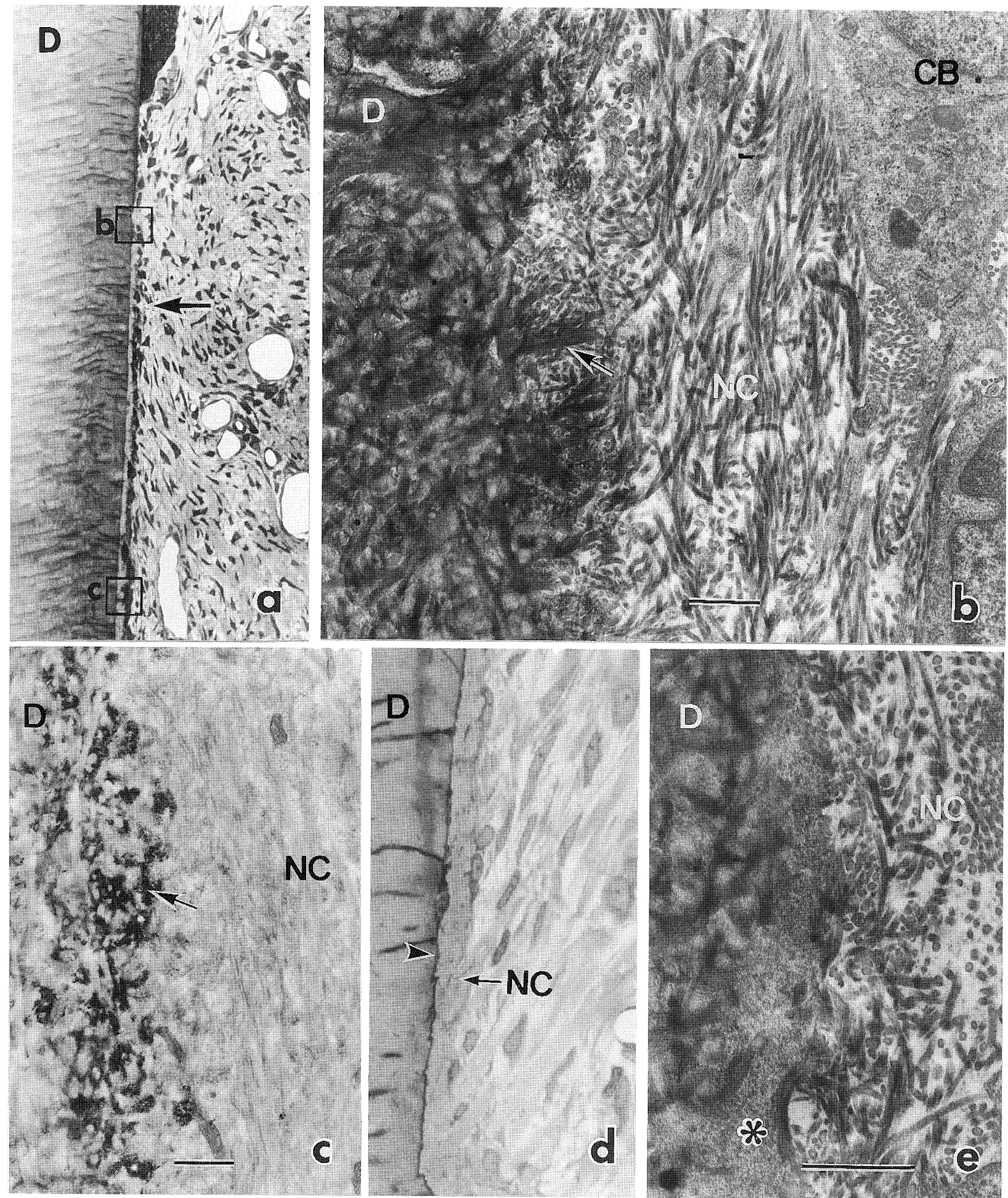

Fig.3: Findings in the HA-demineralized experimental group at 8 weeks after surgery.

a: Light microscopic photograph. New cementum (arrow) matrix and functionally oriented fibers are seen on non resorbed dentin (D) surface adjacent to the apical end of regenerated junctional epithelium. Toluidine blue staining $(\times 160)$.

b: Electron microscopic photograph of area b in Fig. a. Exposed dentin matrix fibers (arrow) exposed by HA demineralization are interlaced to the newly formed cementum (NC) matrix fibers. D: dentin. CB: cementoblast. Tannic acid staining $(\times 11,400$, Bar: $1 \mu \mathrm{m})$.

c: Electron microscopic photograph of apical position, area c, in Fig a. Amorphous granular patches (arrow) are frequently deposited on exposed dentin fibers and new cementum matrix is formed around them. Uranyl acetate and lead citrate staining $(\times 9,500$, Bar: $1 \mu \mathrm{m})$.

d: Light microscopic photograph from the most apical position of demineralized dentin surface. Basophilic line (arrow head) is recognized between dentin (D) surface and the new cementum (NC) matrix. Toluidine blue staining $(\times 640)$.

e: Electron microscopic photograph of border zone between the dentin surface and the new cementum matrix in Fig d. New cementum (NC) matrix fibers are formed parallel and perpendicular to the amorphous granular layer $(*)$ of dentin (D) surface. Tannic acid staining $(\times 19,000$, Bar: $1 \mu \mathrm{m})$. 


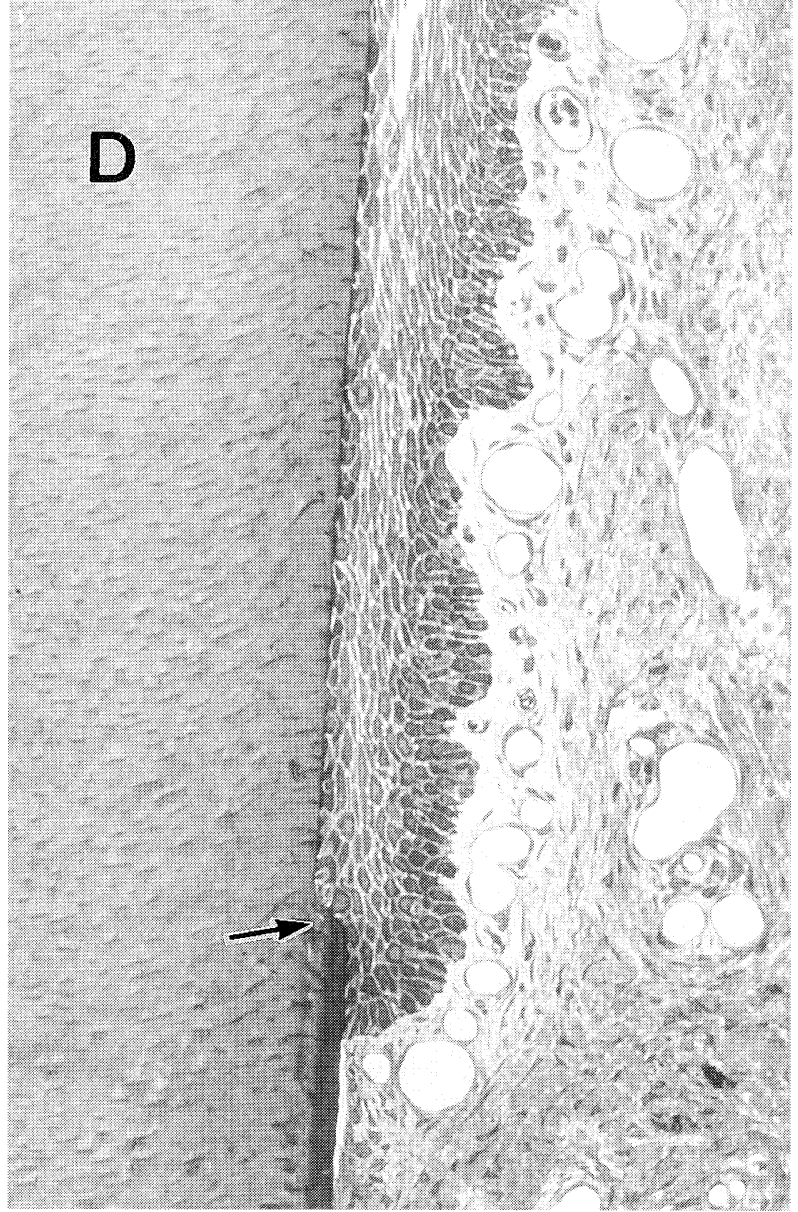

Fig. 4: Light microscopic photograph of non HA-demineralized control group at 8 weeks after surgery. The regenerated junctional epithelium covers the planed dentin (D) surfaces, and no new connective tissue attachment is observed. Arrow: the most apical end of instrumented dentin surface. Toluidine blue staining $(\times 128)$.

osseointegrated implants (24), and that around implanted hydroxyapatite granules (25). It has been suggested that this granular layer may include sialoprotein and osteopontin $(24,26)$, which are expressed in developing teeth and bone (27) and may act to promote cell adhesion (28).

After citric acid (16-18) and phosphate acid (29) conditioning, regenerative cementogenesis may occur by interdigitating and interlacing of newly formed cementum matrix fibers and fibers exposed by dentin demineralization. It seems that HA-demineralization exposes less dentin matrix fibers than demineralization with citric or phosphoric acid (15). Since there has been little previous information about dentin fibers exposed by HA-demineralization, we can not make any further conclusion. In a few studies of root conditioning using tetracycline $(30,31)$, it was suggested that the number of dentin matrix fibers exposed by tetracycline treatment is smaller than those seen after citric acid conditioning.

An important point to notice in this study is that, on HA-demineralized dentin surfaces, the interaction of exposed dentin fibers and newly formed collagen fibers is through a granular amorphous layer which is present on the dentin surface. This interaction may not require pre- vious dentin resorption.

Our findings experimentally revealed the effectiveness of HA-demineralization on periodontally diseased root surfaces for induction of new cementum formation. Subsequently, histometric studies on the gain of new attachment after HA-demineralization in comparison with tetracycline and citric acid treatment are required for the clinical usage of HA as a root surface conditioner in conventional periodontal surgery or GTR therapy.

\section{Acknowledgement}

This study was supported in part by Grant-in-Aid for Scientific Research from the Ministry of Education of Japan (No. 07672076).

\section{References}

1. Hancock EB. Regeneration procedures. In: Nevis M, Becker W, Kornman K, eds. Proceedings of the World Workshop in Clinical Periodontics, Princeton: The American Academy of Periodontology, 1989; VI1-VI20.

2. Takata T. Oral wound healing concepts in periodontology. In: Williams RC, Yukna RA, Newman MG, eds. Current Opinion in Periodontology, Current Science, Philadelphia. 1994; 119-27.

3. Urist MR, Huo YK, Brownell AG, et al. Purification of bovine morphogenetic protein by hydroxyapatite chromatography. Proc Natl Acad Sci USA 1984; 81: 373-5.

4. Urist MR. Bone histogenesis and morphogenesis in implants of demineralized enamel and dentin. Oral Surg 1971; 29: 88102 .

5. Bang $\mathrm{G}$ and Urist MR. Bone induction chambers in matrix of decalcified dentin. Arch Surg 1967; 4: 781-9.

6. Inoue T, Deporter DA and Melcher AH. Induction of cartilage and bone by dentin demineralized in citric acid. $J$ Periodont Res 1986; 21: 243-55.

7. Yeomans JD and Urist MR. Bone induction by decalcified dentin implanted into oral, osseous and muscle tissues. Arch Oral Biol 1967; 12: 999-1008.

8. Register AA, Scopp IW, Kassouny DY, et al. Human bone induction by allogenic dentin matrix. J Periodontol 1972; 43: 45967.

9. Kawai T and Urist MR. Bovine tooth-derived bone morphogenetic protein. J Dent Res 1989; 68: 1069-74.

10. Register AA. Bone and cementum induction by dentin demineralized in situ. J Periodontol 1973; 44: 49-58.

11. Register AA and Burdick FA. Accelerated reattachment with cementogenesis to dentin demineralized in situ. I. Optimum range. J Periodontol 1975;46: 646-55.

12. Register AA and Burdick FA. Accelerated reattachment with cementogenesis to dentin, demineralized in situ. II Defect repair. J Periodontol 1976; 47: 497-505.

13. Kanou T, Ogawa T, Fujitani Y, et al. New cementum formation to the denuded dentin surfaces treated with hydrochloric acid in the periodontal wounds. J Hiroshima Univ Dent Soc 1992; 21: 120-46.

14. Fujitani Y, Ogawa T, Hirohata H, et al. Connective tissue reattachment to denuded dentin surfaces treated with 
hydrochloric acid. J Japan Soc Periodont 1992; 34: 446-55. 15. Ogawa T, Fujitani Y, Kawaguchi H, et al. Ultrastructure of cementogenesis at dentin surfaces treated with hydrochloric acid. J Japan Soc Periodont 1992; 34: 846-56.

16. Frank RM, Fiore-Donno G and Cimasoni G. Cementogenesis and soft tissue attachment after citric acid treatment in a human. J Periodontol 1983; 54: 389-401.

17. Selvig KA, Bogle G and Clafley NM. Collagen linkage in periodontal connective tissue reattachment. An ultrastructural study in beagle dogs. J Periodontol 1988; 59: 758-68.

18. Polson AM and Hames PJ. Cell and fiber attachment to demineralized dentin. A comparison between normal and periodontitis-affected root surfaces. J Clin Periodontol 1987; 14: $357-65$.

19. Frank RM, Fiore-Donno G, Cimasoni G, et al. Ultrastructural study of epithelial and connective gingival reattachment in man. J Periodontol 1974; 45: 626-35.

20. Ogawa T, Hirohata H, Kawaguchi H, et al. Histopathological study on regeneration of dento-gingival junction on periodontally diseased root surfaces following flap surgery in beagle dogs. In: Ishikawa J, Kawasaki H, Ikeda K, et al, eds. Proceedings of the 3rd Meeting of International Academy of Periodontology, Kyoto: International Academy of Periodontology 1988: 343-6.

21. Schupbach P, Gaberthuelt T, Lutz F, et al. Periodontal repair of regeneration: Structures of different types of new attachment. J Periodont Res 1993; 28: 281-93.

22. Knox B and Aukhil I. Ultrastructural study of experimental cementum regeneration in rats. $J$ Periodont Res 1988; 23: 60-7.

23. Bosshardt DD and Schroeder HE. How repair cementum becomes attached to the resorbed roots of human permanent teeth. Acta Anatomica 1994; 150: 253-66.
24. Nanci A, McCarthy GF, Zalzal S, et al. Tissue response to titanium implants in the rat tibia: Ultrastructural immunocytochemical and lectin-cytochemical characterization of the bone-titanium interface. Cells and Materials 1994; 1: 1-30.

25. Kawaguchi H, Ogawa T, Shirakawa M, et al. Ultrastructural and ultracytochemical characteristics of multinucleated cells after hydroxyapatite implantation into rat periodontal tissue. $J$ Periodont Res 1992; 27: 48-54.

26. Kawaguchi $\mathrm{H}$, McKee MD, Okamoto $\mathrm{H}$, et al. Immunocytochemical and lectin-gold characterization of the interface between alveolar bone and implanted hydroxyapatite in the rat. Cells and Materials 1993; 3: 337-50.

27. Chen J, Singh K, MukherJee BB, et al. Developmental expression of osteopontin (OPN) mRNA in rat tissues: Evidence for a role for OPN in bone formation and resorption. Matrix 1993; 13: 113-23.

28. D'Errico JA, Sauk JJ, Prince CW, et al. Osteopontin adhesion receptors on gingival fibroblasts. $J$ Periodont Res 1995; 30: 34-41.

29. Heritier M. Ultrastructural study of new connective tissue attachment following phosphoric acid application on human dentin. J Periodontol 1983; 54: 515-21.

30. Terranova VP, Franzetti LC, Hic S, et al. A biochemical approach to periodontal regeneration. Tetracycline treatment dentin promotes fibroblast adhesion and growth. $J$ Periodont Res 1986; 21: 330-7.

31. Frantz B and Polson A. Tissue interactions with dentin specimens after demineralization using tetracycline. J Periodontol 1988; 59: 714-21.

(Acceped for publication March 25, 1996) 